\title{
Use of Verbal Autopsy as a Proxy to Determine the Possible Cause of Neonatal Deaths
}

\author{
Baghel $\mathrm{B}^{1}$, Bansal AK
}

${ }^{1}$ Dr. Bhagat Baghel, Assist. Professor, MBBS, MD, Dept. of Paediatrics, ${ }^{2}$ Dr A.K. Bansal, MBBS, MD, Professor, Dept. of Preventive and Social Medicine. Both from the Government Medical College, Jagdalpur, India.

Address for Correspondence: Dr. Bhagat Bhagel, E-mail: bhagatbaghel75@yahoo.com

\begin{abstract}
Introduction: Information on causes of death is extremely important for policy making, planning, monitoring, field research, future management statergies and epidemic awareness. The best method of finding the cause of death is by post mortem examination but since this is difficult, post death analysis by verbal autopsy is a good method to determine the same. Objective: To asses the role of verbal autopsy method in the investigation of neonatal death and to determine the probable, causes of neonatal death. Materials and Methods: A pre-tested questionnaire in Hindi was administered to 50 mothers and/or next of kin or other care givers of the deceased residing in villages around $200 \mathrm{Kms}$. of Bhopal and in urban slums of Municipal Corporation, Bhopal. Results: $84 \%$ of the total death occurred with in seven days of birth, $88 \%$ of death occurred in villages where health facilities were available. As per verbal autopsy $36 \%$ and $20 \%$ of the infants died because of Birth asphyxia and Respiratory Distress Syndrome respectively and further $2 \%, 4 \%$ and $6 \%$ because of neonatal tetanus, hypothermia and other causes respectively. Conclusion: Verbal autopsy could be one of the possible cost effective and a reliable tool for determining the causes of neonatal deaths at present.
\end{abstract}

Key words: Verbal Autopsy, Neonatal death, Reliable respondents and category of villages.

\section{Introduction}

nformation on causes of neonatal death is extremely important for policy making, planning, monitoring, field research comparison and epidemic awareness. The exact cause of death can be known by post partum autopsy. How ever in developing countries like India where large number of deaths are not medically certified, this critical information is usually incomplete and of poor quality. Since this situation is not going to change in near future, there is an urgent need to develop an alternative method of obtaining information on the causes of death. In these difficult situations post death analysis by verbal autopsy is the only ray of hope to determine the possible cause of neonatal deaths based on an interview with mother / next kin or other care givers. This study has been conducted to identify the under lying cause and determinants of infants deaths and to determine the use of verbal autopsy as a proxy of possible cause of neonatal deaths.

\section{Materials and Methods}

This study was conducted in urban slum areas of Bhopal and villages around Bhopal within 200

Kilo-meters(Kms). During the period from October 2002 to November 2003. The study incorporated in 50 neonatal details, which were randomly slected. Questionaire was prepared with prestructured schedule in which questions were explained to care giver in Hindi by a paediatrician, before the interview verbal consent was taken in each and every case. Sufficient time was given to recall the events during illness. It took 30-40 minutes for the completion of interview. The recall period allowed was six months from the time of death. The proforma had a total of 11 Sections.

\section{Section1:}

Background Information: Which included the mother and father's name, gender, age, address, 
category of village, relationship of main respondent to diseased baby, reliability of respondent, place of delivery, baby born alive or dead etc.

Category of villages: It reflected the health service status and infrastructure of the village. Villages were categorized in to three groups on the basis of following criteria:-

1. Availability of health facility viz. Sub Health Centre / Primary Health Center/ Community Health Center/ Govt. Hospital / Private Hospital / Qualified Allopathic Doctor etc. Yes / No

2. Village connected with the nearest town by road/ Concrete road. Yes / No

3. Availability of public transport system three or more times a day. Yes / No

4. Drinking water facilities available in the house or within 15 minutes walking distance. Yes / No

Category "A" - If the answer of three or more of the above questions is yes.

Category "B" - If the answer to one or two of the above questions is yes.

Category "C" - If the answer to all of the above questions is no.

Reliability of Respondents: Respondent are categorized in to three groups as per their reliability on the basis of following criteria:-

Category "A" Reliability Good: - Respondent was present with the baby most of the time during illness leading to death.

Category "B" Reliability Fair: - Respondent was present with the baby only for some time during illness leading to death.

Category "C" Reliability Poor: - Respondent was not present with the baby during illness leading to death but he is the only person available at the time of interview.

\section{How was the babay}

Live birth:- Sign's of life are cry, breathing, heart beat, chest movement, limb movement. Presence of one or more will confirm live birth.

Still birth:- A baby without any of the signs of life described above.

Fullterm:- period of amenorrhea is more than 37 weeks and size of the baby is average.
Preterm:- Period of amenorrhea is less than 37 weeks \& size of the baby is below average.

50 Mothers/next kin/ care givers were interviewed over a period of 12 months.

\section{Section 2:}

Open questions regarding available hospital records.

\section{Section 3:}

Antenatal (Including Antenatal checkup, vaccination, period of amenorrhea, ante partum bleeding), natal (Leaking, duration of labour, mode of delivery, size of baby) and postnatal history of mother.

\section{Section 4 to 11:}

Involved diagnosis of neonatal death, diagnosis was made on the basis of the answer given by the care giver.

1. Birth Asphyxia: It was suspected when there was history of any one of the following: difficulty in labour, delayed cry, No normal breathing after 5 mints of birth and convulsion during $1^{\text {st }} 3$ day's of Life. Diagnosis of Birth Asphyxia was strengthening by Absence of sucking and swallowing on $1^{\text {st }} 3$ days of Life.

2. Neonatal Sepsis Complex: It was suspected when the baby had any of the following: Refusal to feed after having fed normally for period of time, Baby become lethargic after an initial period of normal activity and convulsion started after $2^{\text {nd }}$ day of Life. It was confirmed by the presence of following history: Umbilical discharge, Hypothermia, Jaundice and Abdominal distension.

3. Respiratory Distress Syndrome: Question asked included: Did baby have difficulty in breathing (fast breathing, chest in drawing and intermittent cessation of breathing).

4. Neonatal Tetanus: Diagnosis was made on the basis of spasm started $72 \mathrm{hrs}$ after birth, spasm induced by light, touch \& noise, baby unable to open mouth while sucking and crying.

\section{Results}

Data from 50 Neonatal deaths were collected and analyzed. On analysis of the collected data it has been revealed that $42(84 \%)$ of the total neonatal death occurred within seven days of the birth $(32 \%$ within 24 hours, $32 \%$ within $2-3$ days and another $20 \%$ within $4-7$ days) Table: 1. 
Table 1: Age distribution of neonatal deaths.

\begin{tabular}{|l|c|c|}
\hline Age at death & $\begin{array}{c}\text { Numbers of } \\
\text { Death }\end{array}$ & Percentage \\
\hline$<24$ hours & 16 & $32 \%$ \\
\hline 1-3 Days & 16 & $32 \%$ \\
\hline 4-7 Days & 10 & $20 \%$ \\
\hline 8-15 Days & 03 & $06 \%$ \\
\hline 16-28 Days & 05 & $10 \%$ \\
\hline Total & $\mathbf{5 0}$ & $\mathbf{1 0 0} \%$ \\
\hline
\end{tabular}

As per sex of neonate $58 \%$ were males in comparison to $42 \%$ females. $88 \%$ of neonates belong to category " $A$ " villages and only $12 \%$ from category " $B$ " villages. None of the neonates come from category " $C$ " villages. As far as the reliability of the respondents is concerned, $98 \%$ of the respondents were of category "A" i.e. their reliability is good while $2 \%$ were of category "B" i.e. their reliability was fair. Regarding place of delivery of the deceased (46\%) were delivered at home, while $44 \%, 6 \%, 2 \%$ and $2 \%$ were ay Govt. Hospital, Sub Health Centre, P.H.C., and Private Hospital respectively. $46 \%$ of the delivery were conducted by doctors, $36 \%$ by Trained Birth Attendant, $12 \%, 4 \%$, and $2 \%$ respectively by relatives or friends, hospital nurse and village nurse.

$66 \%$ of total neonatal death took place at home while24\% occurred on way to hospital. Only 6\% (2\% each at Sub Centre, P.H.C. and private hospital) death occurred in health facilities (Table 2).

Table 2: Place of neonatal deaths.

\begin{tabular}{|l|c|c|}
\hline $\begin{array}{l}\text { Place of Neonatal } \\
\text { Death }\end{array}$ & $\begin{array}{c}\text { Numbers of } \\
\text { Death }\end{array}$ & Percentage \\
\hline Home & 33 & $66 \%$ \\
\hline During Transporting & 12 & $24 \%$ \\
\hline Sub-Centre & 01 & $02 \%$ \\
\hline P.H.C. & 01 & $02 \%$ \\
\hline Private Hospital & 01 & $02 \%$ \\
\hline Others & 02 & $04 \%$ \\
\hline Total & $\mathbf{5 0}$ & $\mathbf{1 0 0} \%$ \\
\hline
\end{tabular}

$80 \%(18 \%+62 \%)$, mother undergo antenatal checkup during pregnancy for 3 or more times (Table 3 ) while, $6 \%$ twice and $4 \%$ mothers only once. There were $10 \%$ mothers who never under gone antenatal checkup.

$84 \%$ of the deceased mothers received two doses of Tetanus Toxoid during pregnancy, $8 \%$ only one dose and the rest $8 \%$ did not received even single dose of Tetanus Toxoid. $62 \%$ neonates were of full term and the rest $38 \%$ were ever preterm. There was no complication in $74 \%$ of the neonates at the time of birth, while $12 \%$ under gone surgical delivery, $2 \%$ Mothers have convulsion and $2 \%$ suffered from excessive bleeding.
Table 3: Antenatal checkup during pregnancy.

\begin{tabular}{|l|c|c|}
\hline $\begin{array}{l}\text { Antenatal } \\
\text { Checkup }\end{array}$ & $\begin{array}{c}\text { Numbers of } \\
\text { Mothers }\end{array}$ & Percentage \\
\hline Not Attended & 05 & $10 \%$ \\
\hline Once & 02 & $04 \%$ \\
\hline Twice & 03 & $06 \%$ \\
\hline Thrice & 09 & $18 \%$ \\
\hline $\begin{array}{l}\text { More Than 3 } \\
\text { Times }\end{array}$ & 31 & $62 \%$ \\
\hline Total & $\mathbf{5 0}$ & $\mathbf{1 0 0} \%$ \\
\hline
\end{tabular}

As per duration of labour $60 \%$ of the mothers took $12-23$ hours, $38 \%$ less than 12 hours in giving birth to the deceased and the remaining $2 \%$ could not reply, $88 \%$ deceased were delivered normally while $12 \%$ by surgical means i.e. caesarian section. $50 \%$ of the neonates cried just after birth while in $46 \%$,there was delay in crying and the remaining $4 \%$ did not have any idea.

Table: 4 reveals that prematurely and neonatal sepsis were two leading cause of neonatal death. In 27 cases cause of neonatal death was single and rest 23 cases causes were multiple.

Table 4: Distribution according to cause (multiple causes) of neonatal deaths.

\begin{tabular}{|c|l|c|c|}
\hline S.No. & Causes of Death & $\begin{array}{c}\text { No. of } \\
\text { Death }\end{array}$ & Percentage \\
\hline 1. & Pre-maturity & 18 & $36 \%$ \\
\hline 2. & Birth Asphyxia & 15 & $30 \%$ \\
\hline 3. & $\begin{array}{l}\text { Neo-natal Sepsis } \\
\text { Complex }\end{array}$ & 18 & $36 \%$ \\
\hline 4. & $\begin{array}{l}\text { Respiratory } \\
\text { Distress Syndrome }\end{array}$ & 10 & $20 \%$ \\
\hline 5. & Hypothermia & 02 & $04 \%$ \\
\hline 6. & Neo-natal Tetanus & 01 & $02 \%$ \\
\hline 7. & Others & 03 & $06 \%$ \\
\hline
\end{tabular}

\section{Discussion}

In the present study $84 \%$ of neonatal deaths occurred within 7 days of birth while Shrivastava 1 observed that only $58.4 \%$ neonatal deaths occurred in early neonatal period. This was lower then the present study and this could be due to the larger sample size of 1000 in Shrivastava's ${ }^{1}$ study in caparison to 50 of the present study. Singhal ${ }^{7}$ showed that $23 \%$ of neonatal deaths were due to Respiratory distress syndrome which was more or less similar to the finding of this study. As per the present study $2 \%$ of the neonatal deaths were due to neonatal Tetanus which was at par of the findings of Shrivastava $^{1}(1.8 \%)$.

In the present study male to female ratio was 1:3:1. Anand $\mathrm{K}^{2}$ and Varkey ${ }^{3}$ also revealed that neonatal 
mortality among males were higher in comparison to females. This could be a simple co-incidental finding. $88 \%$ of Neonatal deaths occurred in "A" Category of villages where well developed infrastructure existed like availability of doctors, PHC, good road connected to town, transport facilities etc. This indicated that just by providing better facilities was going to help much until and unless changes in the behavior of the community are focused, rather than only utilization of health services.

Reliability of respondents showed that $98 \%$ of the respondents were categorized "A" i.e. their reliability was good or in other terms we could say that the information provided by them were reliable. This was a very important land mark in using verbal autopsy as a proxy to determine possible causes of neonatal deaths. Reliability of respondent is one of the important pillars in the proxy war because in verbal autopsy one fully depends upon the information provided by the respondents. $46 \%$ neonatal deaths were those who delivered at home while Bang $\mathrm{AT}^{4}$ in their study found that $95 \%$ were home deliveries. This difference was again because of lower simple size in Bang's study. $52 \%$ of diseases had delivered by trained person (Dai/nurses etc.). $88 \%$ of the neonatal deaths $(66 \%$ of neonatal deaths occurred at home and $12 \%$ on way to hospital) could be averted if they have been referred at proper time or the community had the knowledge of the warning signals so that they themselves go to the designated health facilities on time. $60 \%$ of the mothers were multiparous in comparison to $40 \%$ primiparous mothers. Here again the importance of timely adoptions of one or the other methods of family planning must be emphasized.

$82 \%$ deliveries were singletons and the remaining $18 \%$ were multiple. This was more or less similar to the finding of the study conducted by Bhatia ${ }^{5}$ who observed that $79 \%$ deliveries were singletons.

In this study it was found that in $10 \%$ of the cases the mothers had not recieived any antenatal checkup, while in $80 \%$ had received three or more than three and the remaining $10 \%$ they received antenatal checkup once or twice only. Similar study done by Varkey found that $88 \%$ of the mothers had received antenatal checkup 3 or more than three times. In the present study $36 \%$ deaths were due to pre-maturity which was more or less similar to the findings $(25.4 \%)$ of Shrivastav ${ }^{1}$. Singhal ${ }^{7}$ and Bhandari ${ }^{8}$ in their study observed that $52 \%$ and $26 \%$ neonatal deaths were due to neonatal sepsis complex respectively which was again more or less similar to the findings of the present study i.e. $36 \%$. Shrivastav ${ }^{1}$ also noted that $23.3 \%$ neonatal deaths occurred due to birth asphyxia while this study showed $30 \%$ which was again more or less similar to the findings of the present study.

\section{Conclusion}

From the above observations and discussions it is concluded that prematurely and neonatal sepsis are the two leading causes of neonatal deaths. Thus the community must be sensitized about the symptoms like; if the neonate becomes lethargic, refuses to feed, have convulsions, abdominal distension, umbilical discharge and hypothermia he/she must immediately consult the doctor. Prematurity is one of the important factors for neonatal mortality, so all preterm deliveries should be timely attended. All measures should be taken to minimize the infections to the newborn. Verbal autopsy could be one of the possible cost-effective and to a great extent a reliable tools for determining the causes of neonatal morbidity and mortality.

\section{Acknowledgements}

The authors are thankfull to Dr. (Mrs.) Rashmi Dwivedi M.D. Prof. and Head of Departmenr Pediatrics, Gandhi Medical College, Bhopal (M.P.) for her guidance, supervision and encouragement in conducting this study. Our thanks also goes to the mothers, next kin and other care givers of the deceased without whose help this study couldn't come in this form.

\section{Funding: Nil \\ Conflict of Interest: None \\ Permission from IRB: Yes}

\section{References}

1. Shrivastava SP. Verbal autopsy determined causes of neonatal deaths. Indian Pediatr 2001;38:10221025.

2. Anand K. Kapoor SK et al. Use of Verbal autopsy by health workers in under five children. Indian Pediatr 2003; 40:766-71.

3. Varkey et al Role of verbal autopsy in investigating the cause of infant deaths in rural wardha. 2003 (unpublished).

4. Bang AT, Bang RA. Diagnosis of causes of childhood deaths in developing countries by verbal autopsy. Suggested criteria World Health Organization 1992;70(4):499-507.

5. Bhatla BD. Neonatal mortality pattern in rural based Medical College Hospital. Indian J. Pediatr 1984; 517:309-312. 
6. Bansal AK, Chandorkar R.K. Knowledge, Brief, and Practice: A study of Tribal Mother about feeding of Infants. Tribal Health Bulletin (I.C.M.R.) 1993; $2(3,4)$.

7. Singhal PK. Neonatal Morbidity and mortality in ICDS Urban slums. Indian Pediatr 1990; 27:485487.
8. Bhandari N, Bahal R. Pathways to infant mortality in urban slums of Delhi, India. J Health, Population Nutr 2002;20(2):148-55.

9. Bhandari B, Bahal R, Bhatnagar V, Bhan MK. Treating sick young infants in urban slum setting: Lancet 1996; 347:1174-75.

\section{How to cite this article?}

Baghel B, Bansal AK. Use of Verbal Autopsy as a Proxy to Determine the Possible Cause of Neonatal Deaths. J Nepal Paedtr Soc 2011;31(1):44-48. 